\title{
THE CARDIAC OUTPUT IN MALE SUBJECTS AS MEASURED BY THE TECHNIQUE OF RIGHT ATRIAL CATHETERIZATION. NORMAL VALUES WITH OBSERVATIONS ON THE EFFECT OF ANXIETY AND TILTING ${ }^{1}$
}

\author{
By E. A. STEAD, JR., J. V. WARREN, A. J. MERRILL, AND E. S. BRANNON \\ (From the Medical Service of the Grady Hospital, and the Department of Medicine, \\ Emory University School of Medicine, Atlanta)
}

(Received for publication August 24, 1944)

The determination of the cardiac output in man has usually been done by indirect methods. The demonstration (1) that mixed venous blood could be obtained by introducing a catheter into the right atrium and the later data (2), showing that this technique is simple and safe, have provided a new method for quantitative studies of the circulation in man. The purpose of this paper is to report the data obtained in the study of normal resting subjects by the catheter technique. Some of these persons were relaxed and quiet; others were nervous and apprehensive.

\section{METHODS}

Physicians, medical students, hospital patients, and paid volunteers served as subjects. They had eaten no food since the evening meal on the night previously and they came to the laboratory at 7:30 a.m. After resting onehalf hour, the procedure was begun. Thirty to 90 minutes later, quantitative studies were made.

The right atrium was catheterized via the median antecubital vein by the technique described by Cournand et al. ( 2 to 4$)$. A slow drip of physiological saline solution was maintained through the catheter during the study. The necessity has been stressed (4) for having the tip of the catheter in the region of the tricuspid valve in order to obtain blood in which the streams from the superior and inferior cavae are fully mixed. Even with this precaution, a sample of mixed venous blood may not be obtained. In 3 subjects, blood from the atrium in the region of the tricuspid valve was found to have a very low oxygen content. Samples taken from the right ventricle or other parts of the atrium led to the conclusion that the catheter had entered the coronary sinus, or an aberrant hepatic vein emptying directly into the atrium.

An inlying needle was placed in the femoral artery, which had previously been well novocainized. Oxygen consumption was measured by collecting expired air for

1 The work described in this paper was done under a contract, recommended by the Committee on Medical Research, between the Office of Scientific Research and Development and the Emory University School of Medicine.
2- or 3-minute periods in a Douglas bag and analyzing its oxygen and carbon dioxide content by the method of Haldane. It was found necessary to bring in air from the outside of the building as the carbon dioxide content of the room air increased appreciably during the experiment. The metabolic rate was recorded as the percentage of deviation from the expected basal metabolism. The oxygen content of the mixed venous and arterial bloods was determined by the method of Van Slyke and Neill (5). The hemoglobin concentration of the blood was measured by diluting the blood with ammonia water and determining the intensity of the color by a photoelectric colorimeter. In the few instances where an arterial puncture was not done, blood from the atrium was saturated with oxygen and its oxygen capacity determined directly. The arterial oxygen content of the blood was then calculated on the assumption that the hemoglobin in the arterial blood was 95 per cent saturated with oxygen. It was not possible to calculate the oxygen carrying capacity of the blood from the concentration of the hemoglobin. Varying amounts of inactive hemoglobin were found in the blood. Similar observations have been reported by other investigators $(6,7)$.

The arterial pressure was recorded optically from the femoral artery by the method of Hamilton (8). The mean arterial pressure was measured by planimetric integration of the area beneath the tracing. The peripheral resistance was recorded in absolute units and calculated by the formula (2) :

$$
\mathrm{R}=\frac{\mathrm{Pm} \text { (mean pressure in } \mathrm{mm} . \mathrm{Hg}) \times 1332}{\text { C.O. (cardiac output in } \mathrm{ml} . \text { per sec.) }}
$$

The mean atrial pressure was measured by a manometer filled with physiological saline solution, a point $5 \mathrm{~cm}$. below the fourth costo-chondral junction being taken as the center of the right atrium. The ventilation was expressed in liters of air per minute per sq. meter at $37^{\circ}$ and the prevailing barometric pressure (9).

Three of these subjects had an intravenous injection of $2 \mathrm{ml}$. of a 20 per cent solution of para-amino hippurate from 15 to 20 minutes before the cardiac output was measured. The disappearance rate of this substance was being determined in an associated study and, as this substance was found to have no effect on the circulation, the data on these patients have been included along with those of other normal subjects. 


\section{RESULTS}

Eleven relatively complete sets of observations were made on 7 medical students and 2 physicians (Table I). These subjects were familiar with the techniques used and had been present when the procedures were carried out on other subjects. In 5 of these experiments, the measurements were made before the removal of blood for an associated study. The subjects had served as donors previously and were not apprehensive about the loss of blood. Eight of the subjects appeared relaxed. The ninth was obviously tense. In the 10 sets of observations on normal, relaxed subjects, the ventilation rate varied from 2.4 to 3.5 , the oxygen consumption per sq. $\mathrm{m}$. from 103 to $133 \mathrm{ml}$. per minute. The arteriovenous oxygen difference ranged from 3.1 to 5.0 and the cardiac output from 4.9 to 7.7 . The cardiac index varied from 2.4 to 3.9 and the mean femoral pressure from 71 to $97 \mathrm{~mm}$. of $\mathrm{Hg}$. The pressure in the right atrium ranged from 15 to $75 \mathrm{~mm}$. of water, the peripheral resistance from 822 to 1580 units. Observations were made on 2 different days on one of these subjects. On the first occasion, the metabolic rate deviation from the expected normal was minus 25 , on the second, minus 13 . Two determinations of the oxygen consumption were done with each experiment. The first set of observations may represent a technical error, but we have not been able to detect it. In the tense subject, WB, the heart rate was rapid, the oxygen consumption was slightly higher than in the others, the cardiac output was greatly increased and the peripheral resistance was extremely low. Five months later, the observations were repeated. The subject was more relaxed, the pulse rate had decreased 18 beats per minute, the cardiac output had fallen to one-half its former level, and the peripheral resistance had risen 400 units. The metabolic rate had decreased from plus 6 to minus 12.

Similar studies were made on 10 colored male patients from the wards of Grady Hospital. Four of the subjects were convalescing from an herniorrhapy, one had asymptomatic neurosyphilis, one diffuse neurofibromatosis, and one submental tuberculous lymphadenitis without any systemic evidence of infection. Three patients were convalescing from acute illness, one from typhus fever, one from infectious hepatitis, and one from lymphocytic choriomeningitis. As a rule, these patients showed somewhat higher ventilation rate and oxygen consumption than did the medical students and physicians. The average oxygen consumption per minute per sq. m. was $139 \mathrm{ml}$., as compared to $121 \mathrm{ml}$. for the students and physicians. It was much more difficult to judge whether these patients were relaxed. In one subject, the metabolic rate was plus 16 . In a second, the pulse rate was 84 beats per minute. Excluding these 2 subjects, the cardiac index varied from 2.3 to 4.1 and the atrial pressure from 0 to plus $85 \mathrm{~mm}$. of water. The cardiac index in the students and physicians who appeared relaxed averaged 3.2. This is not significantly different from the average figure of 3.6 found in the colored patients.

Three negro males were studied before and after venesection. These subjects came into the hospital the morning of the experiment. They had never given blood and were naturally somewhat apprehensive. The oxygen consumption in these patients was definitely above the level of the controls and the cardiac output was elevated. The first subject, WP, was of particular interest because observations were made at 3 different times. By the third experiment, he was well relaxed. In the first 2 experiments, the oxygen consumption was 14 and 8 per cent higher than in the third one, while the cardiac output was 47 and 65 per cent higher than in the third set of observations.

Observations on the effect of gravity on the cardiac output were made in 5 normal subjects and one patient with hyperthyroidism. After the cardiac output was measured with the subject in the recumbent position, the table was tilted to an angle of approximately $70^{\circ}$ from the horizontal, the feet resting against an upright foot support. The arms hung loosely at the thighs and the persons were relaxed except for the use of muscles necessary to the maintenance of the semi-erect posture. Care was taken not to move the legs or to tighten and relax the leg muscles alternately. The position of the catheter was checked by fluoroscopy and after 5 to 8 minutes of motionless standing the cardiac output was measured. The results are given in Table II. In each instance, 
TABLE II

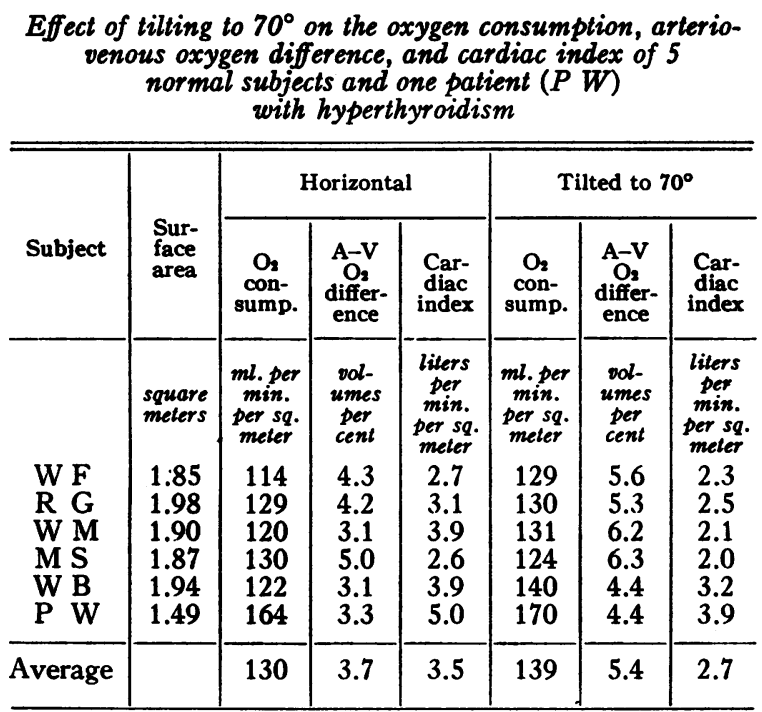

the arteriovenous oxygen difference increased and the cardiac output decreased. In the semi-erect position, the increase in arteriovenous oxygen difference was somewhat more striking than the fall in cardiac output, because the metabolic rate was usually higher with the patient in the semierect than in the horizontal position. In one subject, 3 specimens of blood were taken from different areas in the right atrium to be certain that the lowering of the oxygen content of the atrial blood was not the result of improper mixing of the blood from the superior and inferior venae cavae. The values found for the oxygen content were similar in the 3 specimens.

\section{COMMENT}

Determination of the cardiac output utilizing mixed venous blood from the right atrium has opened a wide field for clinical investigation. This technique, however, has many sources of error so that small changes are difficult to interpret. The method is more accurate when the arteriovenous oxygen difference is large. When the oxygen consumption remains constant, the relationship between the cardiac output and the arteriovenous oxygen difference is a logarithmic one. Thus, with an arteriovenous oxygen difference of 8 , an increase of one volume per cent will cause a decrease in cardiac output of only 12 per cent. With an arteriovenous difference of 2 , an increase of one volume per cent will cause a 33 per cent decrease in output (Figure 1).

Other investigators (2) have taken repeated samples within a few minutes' time in a series of 11 subjects with the subject in an apparently steady state. The mixed venous oxygen in successive samples varied as much as 0.5 volume per cent. With an arteriovenous oxygen difference of 4 , this much variation would cause a 12.5 per lent variation in cardiac output. These same authors have emphasized the care that must be taken in locating the tip of the catheter close to the tricuspid valve. Even then variations in oxygen content because of admixture of blood from the coronary sinus cannot be controlled. The collection of 2-minute samples of air for determining oxygen consumption introduces an error which probably varies considerably from subject to subject. In any given subject, it is difficult to be certain that he is relaxed and that an increase or decrease in cardiac output attributed to

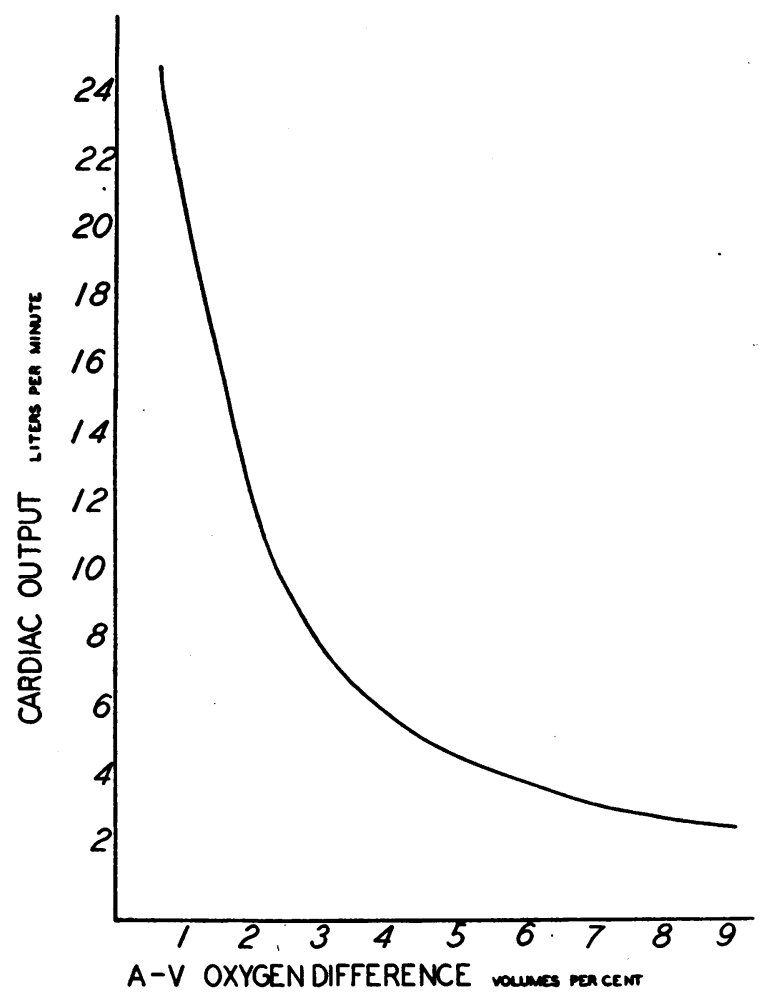

Fig. 1. The Relationship Between the Cardiac Output and the Arteriovenous Oxygen Difference, Assuming that the Oxygen Consumption Remains Constant 
an experimental procedure is not merely the result of variation in the degree of relaxation.

These data demonstrate that, in normal adult males, the cardiac output at rest varies greatly, ranging from 4.2 to 14.8 liters per minute. The output per minute per sq. m. of body surface (cardiac index) ranged from 2.3 to 7.7. It was obvious that certain of the subjects were not well relaxed and that, therefore, the circulation was hyperactive. The data from these subjects should not be used in determining the normal range of the various functions of the circulation in relaxed subjects under basal conditions. It was arbitrarily decided to exclude from the normal relaxed group subjects in whom the metabolic rate was over plus 10 and in whom the heart rate was over 82 beats per minute. From the analysis of the data on 19 studies in 18 normal subjects, the following range of normal values is obtained: Ventilation rate from 2.4 to 5.6 with an average of 3.4 ; oxygen consumption per sq. $\mathrm{m}$. per minute from 103 to 146 with an average of $128 \mathrm{ml}$; arteriovenous oxygen difference from 3.1 to 6.1 with an average of 4 volumes per cent; cardiac output per minute per sq. $\mathrm{m}$. of body surface from 2.3 to 4.1 with an average of 3.3 ; mean femoral pressure (data on 13 subjects) from 71 to 98 with an average of $85 \mathrm{~mm} . \mathrm{Hg}$; atrial pressure from 0 to 85 with an average of $31 \mathrm{~mm}$. of water; peripheral resistance from 820 to 1750 with an average of 1160 units.

Cournand et al. have reported observations on 15 normal subjects (2). The data given there are recorded in the next to last line of Table I. Our subjects had lower pulmonary ventilation, a lower oxygen consumption, and a somewhat smaller arteriovenous oxygen difference. A similar range of cardiac index is noted in the two studies. The average atrial pressure in the two series was not significantly different. The values for the arteriovenous oxygen differences recorded here are in general agreement with those found in normal subjects by McMichael and Sharpey-Shafer (10).

The values for the cardiac output as measured by the catheter method are greater than those obtained by the acetylene technique. This has been a consistent finding in each of the reported series $(2,10,11)$.

A decrease in cardiac output occurred when the body was tilted to an angle of $70^{\circ}$ from the horizontal. The subjects in these experiments were partially supported by leaning against the table and therefore the experiments are not directly comparable to those in which the subject has been standing relaxed, but without support. Grollman (11), using the acetylene method, found that the cardiac output was unchanged when the patient stood in a relaxed position. The arteriovenous difference increased when the patient stood, but the oxygen consumption also increased so that the cardiac output remained unchanged. One author (12), using the acetylene method, found that the cardiac output with the subject standing in a relaxed position averaged 9 per cent less than with the subject in the horizontal position. More recently, the same author (10), using the catheter technique, found that the cardiac output in the relaxed standing position was 25 per cent lower than in the recumbent position. Others (13), using the ballistocardiograph to measure the cardiac output, found no consistent change when observations were made with subjects in the recumbent and relaxed standing positions. Our data are not comparable because our subjects were partially supported and not standing erect.

Seven sets of observations on 5 subjects were not included in the data on normal basal resting subjects. In 5 out of the 7 experiments, the resting pulse rate exceeded 82 beats per minute. In 5 of the 7, the metabolism was over plus 10 . The average figures for the various aspects of the circulation in this group of subjects with some evidence of anxiety are given in the last line of Table I. The average $\mathrm{A}-\mathrm{V}$ oxygen difference was 3.1, the average cardiac index 5.5, and the average peripheral resistance 827 . It is of interest to note that the average oxygen consumption with anxiety was 23 per cent greater than in the more relaxed subjects, while the cardiac output was increased 66 per cent above that found in the relaxed subjects. The validity of this observation is supported by the data on the 2 subjects in whom repeat determinations were made at a subsequent date. In each subject, anxiety produced a much greater rise in cardiac output than in metabolism. 
TABLE I

Observations on 22 normal male subjects in the horizontal position No food for 12 hours before experiment

\begin{tabular}{|c|c|c|c|c|c|c|c|c|c|c|c|c|c|c|c|c|c|}
\hline \multirow[b]{2}{*}{ 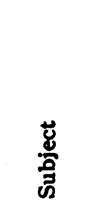 } & \multirow[b]{2}{*}{$\ddot{\leftrightarrow}$} & \multirow[b]{2}{*}{$\begin{array}{l}\text { 莒 } \\
3 \\
3\end{array}$} & \multirow{2}{*}{ 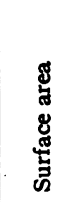 } & \multirow{2}{*}{ 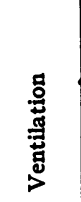 } & \multirow{2}{*}{ 总 } & \multirow{2}{*}{ 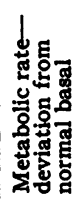 } & \multirow{2}{*}{ 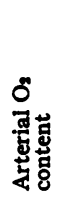 } & \multirow{2}{*}{ 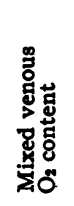 } & \multirow{2}{*}{ 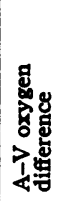 } & \multirow{2}{*}{ 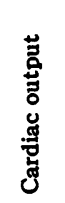 } & \multirow{2}{*}{ 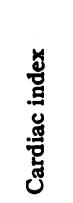 } & \multicolumn{3}{|c|}{$\underset{\text { pressure }}{\text { Femorial }}$} & \multirow[b]{2}{*}{ 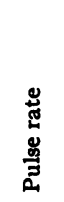 } & \multirow{2}{*}{ 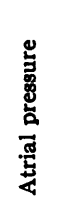 } & \multirow[b]{2}{*}{ 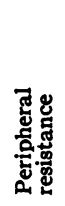 } \\
\hline & & & & & & & & & & & & 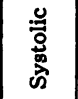 & 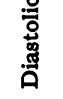 & $\sum_{\Sigma}^{5}$ & & & \\
\hline & years & kgm. & $\begin{array}{l}\text { square } \\
\text { meters }\end{array}$ & $\begin{array}{c}\text { liters } \\
\text { per } \\
\text { min. } \\
\text { per } \\
\text { sq. } m .\end{array}$ & $\begin{array}{c}\text { ml. per } \\
\text { min. } \\
\text { per } \\
s q . m .\end{array}$ & $\begin{array}{l}\text { per } \\
\text { cent }\end{array}$ & \multicolumn{3}{|c|}{ volumes per cent } & $\begin{array}{c}\text { liters } \\
\text { per } \\
\text { min. }\end{array}$ & $\begin{array}{c}\text { livers } \\
\text { per } \\
\text { min. } \\
\text { per } \\
\text { sq. } m .\end{array}$ & \multicolumn{3}{|c|}{$m m . \mathrm{Hg}$} & $\begin{array}{c}\text { beats } \\
\text { per } \\
\text { min. }\end{array}$ & $\mathrm{mm}_{\mathbf{H} 2 \mathrm{O}}$ & $\begin{array}{l}\text { abso- } \\
\text { lute } \\
\text { units }\end{array}$ \\
\hline \multicolumn{18}{|c|}{ Group One-Normal subjects-Students and physicians } \\
\hline $\begin{array}{l}\text { ES } \\
\text { WM } \\
\text { WM } \\
\text { WLM } \\
\text { CG } \\
\text { WS* } \\
\text { WF } \\
\text { MS } \\
\text { RG* } \\
\text { WB } \\
\text { WB }\end{array}$ & $\begin{array}{l}35 \\
23 \\
23 \\
22 \\
22 \\
25 \\
23 \\
22 \\
23 \\
23 \\
23\end{array}$ & $\begin{array}{l}82.6 \\
72.6 \\
72.6 \\
82.1 \\
68.9 \\
81.7 \\
68.0 \\
72.6 \\
78.5 \\
75.8 \\
76.2\end{array}$ & $\begin{array}{l}2.04 \\
1.90 \\
1.90 \\
2.04 \\
1.91 \\
2.04 \\
1.85 \\
-1.87 \\
1.98 \\
1.93 \\
1.94\end{array}$ & $\begin{array}{l}3.1 \\
2.4 \\
2.6 \\
2.7 \\
3.5 \\
3.1 \\
2.5 \\
2.9 \\
2.6 \\
2.6 \\
2.5\end{array}$ & $\begin{array}{l}109 \\
103 \\
120 \\
121 \\
131 \\
133 \\
114 \\
130 \\
129 \\
146 \\
122\end{array}$ & $\begin{array}{l}-18 \\
-25 \\
-13 \\
-12 \\
-5 \\
-2 \\
-12 \\
-6 \\
-7 \\
+6 \\
-12\end{array}$ & $\begin{array}{l}18.3 \\
19.4 \\
19.0 \\
21.2 \\
18.5 \\
19.2 \\
19.4 \\
20.6 \\
18.6 \\
20.2 \\
19.5\end{array}$ & $\begin{array}{l}13.7 \\
16.2 \\
15.9 \\
16.5 \\
14.7 \\
15.7 \\
15.1 \\
15.6 \\
14.4 \\
18.3 \\
16.4\end{array}$ & $\begin{array}{l}4.6 \\
3.2 \\
3.1 \\
4.7 \\
3.8 \\
3.5 \\
4.3 \\
5.0 \\
4.2 \\
1.9 \\
3.1\end{array}$ & $\begin{array}{r}4.9 \\
6.1 \\
7.4 \\
5.3 \\
6.5 \\
7.7 \\
4.9 \\
4.9 \\
6.1 \\
14.8 \\
7.6\end{array}$ & $\begin{array}{l}2.4 \\
3.2 \\
3.9 \\
2.6 \\
3.4 \\
3.8 \\
2.7 \\
2.6 \\
3.1 \\
7.7 \\
3.9\end{array}$ & $\begin{array}{r}136 \\
116 \\
\ddagger 110 \\
112 \\
141 \\
117 \\
\ddagger 110 \\
136 \\
\ddagger 120 \\
128 \\
113\end{array}$ & $\begin{array}{l}73 \\
62 \\
80 \\
55 \\
\cdot 75 \\
63 \\
60 \\
73 \\
76 \\
66 \\
66\end{array}$ & $\begin{array}{l}91 \\
81 \\
\\
71 \\
96 \\
79 \\
\\
97 \\
\\
88 \\
85\end{array}$ & $\begin{array}{r}64 \\
60 \\
58 \\
60 \\
72 \\
79 \\
69 \\
80 \\
69 \\
100 \\
82\end{array}$ & $\begin{array}{r}55 \\
45 \\
35 \\
35 \\
35 \\
15 \\
55 \\
75 \\
\\
0 \\
\mathbf{3 5}\end{array}$ & $\begin{array}{r}1515 \\
1055 \\
\\
1085 \\
1160 \\
822 \\
1580 \\
\\
475 \\
880\end{array}$ \\
\hline \multicolumn{18}{|c|}{ Group Two-Normal subjects-Hospital patients without clinical evidence of infection } \\
\hline $\begin{array}{l}\text { LM* } \\
\text { BJ† } \\
\text { HB } \\
\text { JC } \\
\text { PM } \\
\text { CL } \\
\text { SL }\end{array}$ & $\begin{array}{l}30 \\
25 \\
26 \\
16 \\
17 \\
33 \\
27\end{array}$ & $\begin{array}{l}73.9 \\
82.1 \\
78.0 \\
56.2 \\
69.6 \\
64.9 \\
66.2\end{array}$ & $\begin{array}{l}1.84 \\
1.99 \\
1.99 \\
1.69 \\
1.78 \\
1.77 \\
1.76\end{array}$ & $\begin{array}{l}4.0 \\
3.3 \\
3.5 \\
4.3 \\
3.8 \\
3.7 \\
3.2\end{array}$ & $\begin{array}{l}138 \\
140 \\
159 \\
130 \\
143 \\
135 \\
129\end{array}$ & $\begin{array}{r}+3 \\
+4 \\
+16 \\
-14 \\
-5 \\
-6\end{array}$ & $\begin{array}{l}20.7 \\
19.6 \\
18.3 \\
17.9 \\
19.6 \\
19.7 \\
16.8\end{array}$ & $\begin{array}{l}14.6 \\
14.9 \\
15.1 \\
13.8 \\
15.6 \\
15.9 \\
13.5\end{array}$ & $\begin{array}{l}6.1 \\
4.7 \\
3.2 \\
4.1 \\
4.0 \\
3.8 \\
3.3\end{array}$ & $\begin{array}{l}4.2 \\
5.9 \\
9.9 \\
5.4 \\
6.4 \\
6.3 \\
6.8\end{array}$ & $\begin{array}{l}2.3 \\
3.0 \\
5.0 \\
3.2 \\
3.6 \\
3.6 \\
3.9\end{array}$ & $\begin{array}{l}129 \\
122 \\
136 \\
120 \\
120\end{array}$ & $\begin{array}{l}71 \\
65 \\
79 \\
63 \\
64\end{array}$ & $\begin{array}{r}92 \\
82 \\
100 \\
81 \\
84\end{array}$ & $\begin{array}{l}72 \\
84 \\
84 \\
65 \\
73 \\
60 \\
64\end{array}$ & $\begin{array}{r}0 \\
-5 \\
40 \\
15 \\
25 \\
25 \\
85\end{array}$ & $\begin{array}{r}1750 \\
1115 \\
807 \\
1200 \\
1045\end{array}$ \\
\hline
\end{tabular}

Group Three-Normal subjects-Hospital patients convalescing from acute infectious disease

\begin{tabular}{l|l|l|l|l|l|l|l|l|l|l|l|l|l|l|l|l|l}
\hline GH & 39 & 77.1 & 1.93 & 5.6 & 130 & -5 & 16.0 & 11.9 & 4.1 & 6.3 & 3.3 & 124 & 68 & 87 & 68 & 10 & 1100 \\
JF & 27 & 58.5 & 1.63 & 4.0 & 146 & +6 & 16.5 & 12.5 & 4.0 & 6.0 & 3.7 & 114 & 60 & 73 & 56 & 60 & 972 \\
YW & 25 & 67.1 & 1.82 & 4.1 & 138 & +1 & 19.2 & 15.8 & 3.4 & 7.4 & 4.1 & 110 & 72 & 76 & 75 & 0 & 823 \\
\hline
\end{tabular}

Group Four-Normal subjects before venesection

\begin{tabular}{l|r|r|r|r|r|r|r|r|r|r|r|r|r|r|r|r|r}
\hline WPt & 32 & 68.0 & 1.74 & 4.8 & 162 & +21 & 15.6 & 12.4 & 3.2 & 8.8 & 5.1 & 126 & 74 & 92 & 75 & 50 & 833 \\
WPt & 32 & 68.0 & 1.74 & 3.3 & 153 & +12 & 14.5 & 11.8 & 2.7 & 9.9 & 5.7 & 141 & 80 & 100 & 80 & 45 & 808 \\
WP & 32 & 68.0 & 1.74 & 4.9 & 142 & +5 & 16.0 & 11.9 & 4.1 & 6.0 & 3.4 & 143 & 75 & 98 & 68 & 50 & 1305 \\
JT' & 31 & 70.8 & 1.84 & 4.6 & 181 & +32 & 18.5 & 15.6 & 2.9 & 11.5 & 6.2 & 165 & 87 & 115 & 112 & 40 \\
IRt & 22 & 72.6 & 1.84 & 4.6 & 160 & +16 & 18.4 & 15.5 & 2.9 & 10.2 & 5.5 & 167 & 94 & 123 & 88 & 30 & 964 \\
\hline
\end{tabular}

Average values obtained from 19 experiments on 18 normal males in the basal state

\begin{tabular}{l|l|l|l|l|l|l|l|l|l|l|l|l|l|l|l|l}
\hline & & & 3.4 & 128 & -7 & & & 4.0 & & 3.3 & 124 & 67 & 85 & 68 & 31 & 1160 \\
\hline
\end{tabular}

Average values for 15 normal subjects reported by Cournand et al. (2)

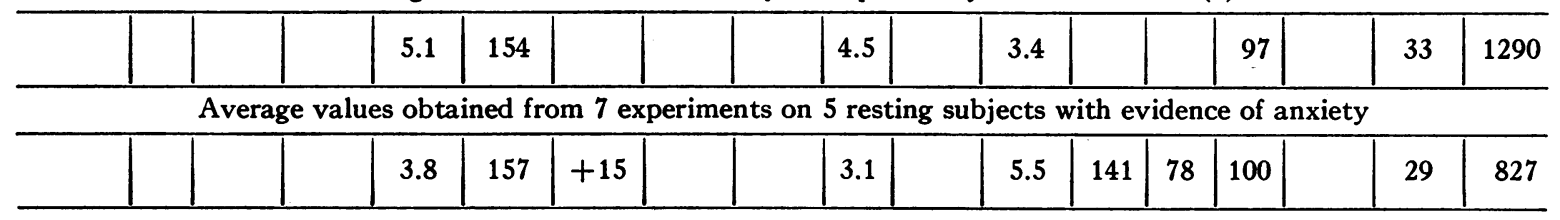

* Received injection of sodium para-amino hippurate.

† Not included in group of relaxed subjects because pulse rate was over 82 or metabolic rate over plus 10 . The average values for these subjects with evidence of increased metabolism and hyperactive circulation are listed in the last line of the table. $\ddagger$ Pressure measued in arm by auscultatory method. 


\section{CONCLUSIONS}

1. Studies on the circulation were performed in 22 normal subjects in the basal state. Samples of mixed venous blood and measurements of the atrial pressure were obtained by inserting a catheter through the antecubital vein into the right atrium. The femoral arterial pressure was recorded optically by the method of Hamilton.

2. Nineteen experiments were carried out on 18 subjects in whom the pulse rate was not above 82 beats per minute and in whom the metabolic rate did not exceed plus 10 . The arteriovenous oxygen difference varied from 3.1 to 6.1 with an average of 4 volumes per cent. The cardiac index (liters per min. per sq. meter) ranged from 2.3 to 4.1 with an average of 3.3. The atrial pressure ranged from 0 to 85 with an average of 31 $\mathrm{mm}$. of water.

3. Seven experiments were performed on 5 normal subjects in whom either the pulse rate exceeded 82 or the metabolic rate plus 10 . These findings were interpreted as evidence of anxiety. The average arteriovenous oxygen difference was 3.1 volumes per cent. The cardiac index averaged 5.5 and the atrial pressure $29 \mathrm{~mm}$. of water. The increase in cardiac output was out of proportion to the increase in oxygen consumption. The rise in cardiac output occurred without any measurable change in atrial pressure.

4. When the subject was tilted to an angle of $70^{\circ}$, the arteriovenous oxygen difference rose and the cardiac output decreased. The average decrease in the cardiac index when the subject was tilted amounted to 23 per cent.

The authors are indebted to Drs. Dickinson Richards, Andre Cournand, and their colleagues for instruction in the techniques utilized in this paper. This work was done with the technical assistance of Miss Maurice Giese, Miss Eloise Cavin, Mrs. Janet Stegeman, and Mrs. Jane Bailey.

\section{BIBLIOGRAPHY}

1. Forssmann, W., Die Sondierung des rechten Herzens. Klin. Wchnschr., 1929, 8, 2085.

2. Cournand, A., Riley, R. L., Bradley, S. E., Breed, E. S., Noble, R. P., Lauson, H. D., Gregersen, M. I., and Richards, D. W., Studies of the circulation in clinical shock. Surgery, 1943, 13, 964.

3. Cournand, A., and Ranges, H. A., Catheterization of the right auricle in man. Proc. Soc. Exper. Biol. and Med., 1941, 46, 462.

4. Goldring, W., and Chasis, H., Hypertension and Hypertensive Disease. Appendix B. The Commonwealth Fund, New York, 1944.

5. Van Slyke, D. D., and Neill, J. M., The determination of gases in blood and other solutions by vacuum extraction and manometric measurement. J. Biol. Chem., 1924, 61, 523.

6. Ammundsen, E., Studies on presence of non-carbonmonoxide-combining (inactive) hemoglobin in blood of normal persons. J. Biol. Chem., 1941, 138, 563.

7. Roughton, F. J. W., Darling, R. C., and Root, W. S., Factors affecting the determination of oxygen capacity, content, and pressure in human arterial blood. Am. J. M. Sc., 1944, 208, 132.

8. Hamilton, W. F., Brewer, G., and Brotman, I., Pressure pulse contours in the intact animal. I. Analytical description of a new high-frequency hypodermic manometer. Am. J. Physiol., 1934, $107,427$.

9. Cournand, A., and Richards, D. W., Jr., Pulmonary insufficiency. I. Discussion of physiological classification and presentation of clinical tests. Am. Rev. Tuberc., 1941, 44, 26.

10. McMichael, J., and Sharpey-Schafer, E. P., Cardiac output in man by a direct Fick method. Brit. Heart J., 1944, 6, 33.

11. Grollman, A., The Cardiac Output of Man in Health and Disease. C. C. Thomas, Baltimore, 1932.

12. McMichael, J., Postural changes in cardiac output and respiration in man. Quart. J. Exper. Physiol., 1937, 27, 55.

13. Starr, I., and Rawson, A. J., The vertical ballistocardiograph; experiments on the changes in the circulation on arising; with a further study of ballistic theory. Am. J. Physiol., 1941, 134, 403. 